IMECE2012-88037

\title{
Mixed Modes Fracture and Fatigue Evaluation for Lithium-ion Batteries
}

\author{
Michael A. Stamps \\ North Carolina State University \\ Department of Mechanical \& Aerospace Engineering \\ 911 Oval Drive, Raleigh, NC, USA \\ mastamps@ncsu.edu
}

\author{
Hsiao-Ying Shadow Huang* \\ North Carolina State University \\ Department of Mechanical \& Aerospace Engineering \\ 911 Oval Drive, Raleigh, NC, USA \\ hshuang@ncsu.edu
}

\begin{abstract}
Lithium ion batteries have become a widely known commodity for satisfying the world's mobile energy storage needs. But these needs are becoming increasingly important, especially in the transportation industry, as concern for rising oil prices and environmental impact from fossil fuels are pushing for deployment of more electric vehicles (EV) or plug in hybrid-electric vehicles (PHEV) and renewable energy sources. The objective of this research is to obtain a fundamental understanding of degradation mechanisms and rate-capacity loss in lithium-ion batteries through fracture mechanics and fatigue analysis approaches. In this study we follow empirical observations that mechanical stresses accumulate on electrode materials during the cycling process. Crack induced fracturing will then follow in the material, degrading the electrical contact surface area and reducing the capacitance of the battery. A fatigue analysis simulation is applied using ANSYS finite element software coupled with analytical models to alleviate these parameters that play the most pivotal roles in affecting the rate-capacity and cycle life of the lithium-ion battery. Our results have potential to provide new models and simulation tools for clarifying the interplay of structure mechanics and electrochemistry while offering an increased understanding of fatigue degradation mechanisms in rechargeable battery materials. These models can aid manufacturers in the optimization of battery materials to ensure longer electrochemical cycling life with high-rate capacity for improved consumer electronics, electric vehicles, and many other military or space applications.
\end{abstract}

\section{ENERGY OUTLOOK}

For decades, petroleum products have been the backbone for transportation in the U.S. and around the world. About 50\% of petroleum consumption is dedicated to the transportation industry while the other $50 \%$ is comprised for electricity generation and industrial or residential use [1]. Today's society has become heavily reliant on oil consumption for its day-to-

\footnotetext{
*Corresponding author
}

day activities, and prices are predicted to keep rising at relatively constant rates (Fig. 1). This over-reliance on petroleum will only stymie the world in the future as oil reservoirs are drained and fuel prices skyrocket. In addition, environmentalist and scientist alike have studied the negative effects of the enormous carbon emissions to our atmosphere. It has been reported that $98 \%$ of all carbon dioxide emissions, the main contributor, come from petroleum fuels [2]. This has induced the drive for 'going green' which has become a worldwide epidemic. Thus, need to reduce our carbon footprint, especially in the petroleum driven transportation sector, is changing the way we design for the future. Government policy has recently set requirements for auto manufactures by year 2016 in which an average of $35.5 \mathrm{mpg}$ and a maximum $\mathrm{CO}_{2}$ exhaust level of 250 grams per mile must be achieved for 'light vehicles' [3]. Therefore researchers have increased efforts in looking for alternative fuels and energy sources such as improved batteries for hybrid and electric vehicle transportation in particular [4].

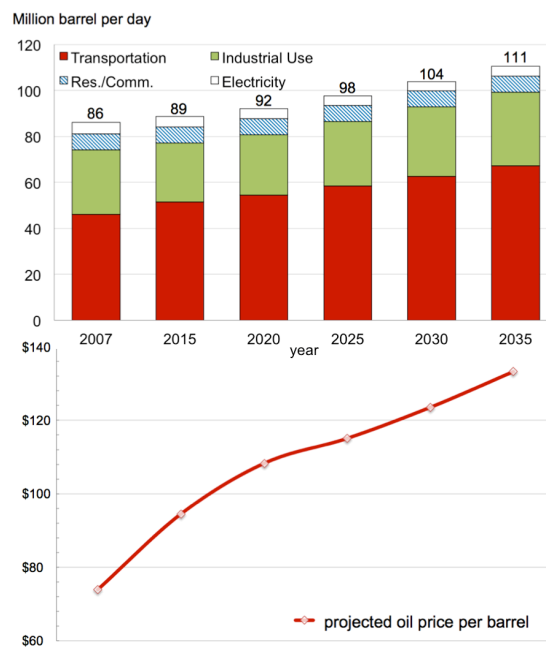

Figure 1: Current and future market trends in the oil industry for transportation, industrial use, residential and electricity generation. Trends show consistent increases in consumption and price through year 2035, but price increases at a slightly higher rate. 
Zero emission electric vehicle (EV) and minimal emission plug-in hybrid electric vehicles (PHEV) are already being manufactured and sold but lack in mass appeal due to limited range and power. Lithium-ion batteries offer great promise for increased power, range and safety for vehicles, but improvements can still be made to increase cycle life, appeal and competitiveness in the automobile market [5]. Figure 2 shows the advantage of EV and PHEV vehicles regarding price and harmful emissions as compared to their gas counterpart of similar size and weight class. Considerable economic and environmental saving advantages are evident for electrically powered vehicles, especially for zero emission EV's which are still considered by many to be in its 'infant' stage of technological design.

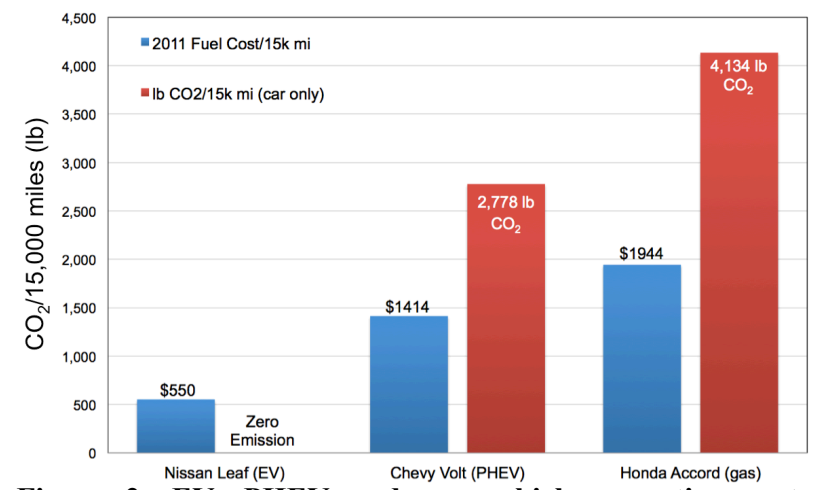

Figure 2: EV, PHEV and gas vehicle operation cost and emissions per 15,000 miles. Gas price is estimated at $\$ 3.60$ per gallon, electricity rate is averaged for $70 \%$ night charge and $30 \%$ day charging.

Not only is oil consumption around the world on the rise, but the demand for electricity is also increasing every year in our technologically driven world. Therefore, production must keep up with demand through the use of additional coal plants, nuclear plants, natural gas facilities and renewables such as wind, hydroelectric, biofuel, geothermal and solar energy among others. In 2010 , about $80 \%$ of electricity generation was obtained from fossil fuels (coal, natural gas, petroleum) while nuclear and renewables contributed about $10.0 \%$ each [6]. Thru the month of December during 2011, U.S. Energy Information Administration (EIA) reports that petroleum products, nuclear and renewables each contributed $77.6 \%, 11.3 \%$, and $11.0 \%$ of U.S. energy production, respectively [7]. This information shows how the market for clean, renewable energy is rapid growing. At the same time, large-scale energy production from coal plants are being replaced with cleaner, natural gas facilities. There is now a need for battery storage devices as a bridge between power generation and consumption more than ever before. Dozens of facilities across the world have recently taken advantage of technology advances by outfitting their facilities with large-scale batteries as backup or primary energy storage devices. Some of these locations include China (10 and $36 \mathrm{MWh}$ facilities), the West Virginia Laurel Mountain wind farm (32 MWh facility) and Oahu, Hawaii (10 MWh wind farm).

\section{$\mathrm{LiFePO}_{4}$ SELECTION AND PERFORMANCE CHARACTERISTICS}

The battery has long been a very important commodity for satisfying the world's mobile energy storage needs. The advantages of lithium-ion batteries over other types or rechargeable batteries such as Nickel-Cadmium and Metal Hydride types lie in their superior energy-to-weight ratio, quicker recharge times, and increased cycle life [8]. It should also be noted that $\mathrm{Co}$ is toxic and Ni may pollute as well, but $\mathrm{LiFePO}_{4}$ is a nontoxic and environmentally benign material.

The lithium-ion battery is composed of three parts: the anode, an electrolyte solvent and the cathode which holds all the active lithium before operation. To charge, an external power source applies an over-voltage, forcing the active Li-ions from the cathode to the anode. When discharging, electrons flow out from the anode through an external wire to form an electrical circuit while Li-ions flow through the electrolyte to the cathode, thus neutralizing the charge [9]. The electrons provide electrical energy to any connected device until the lithium ion extraction and insertion processes are complete. A multitude of materials can be implemented for each battery component but anodes usually consist of a layered carbon structure, silicon nano wires, or titanate material whereas cathodes most commonly utilize an intercalated lithium compound such as $\mathrm{LiFePO}_{4}, \mathrm{LiMn}_{2} \mathrm{O}_{4}$ or $\mathrm{LiCoO}_{2}[10,11]$. A common electrolyte solution consists of an organic solvent containing lithium salt.

Batteries are now seeing performance increases that allow for high power applications including anything from vehicles and laptop computers to orbiting satellites and electric tools. As transportation markets are coming into play, a battery's environmental impact and durability characteristic against climate variation are becoming very important in the material selection and design as well. Many different types of cathode materials are used to outfit today's electronic devices, each with its set of pros and cons. $\mathrm{LiCoO}_{2}$, for instance, is popular in small, consumer electronics as it offers excellent power, energy density and charging/discharging capabilities. But this material lacks thermal stability, which raises concern for safety sensitive applications such as EV, HEV and PHEV [10]. $\mathrm{LiMn}_{2} \mathrm{O}_{4}$ offers better thermal stability making it a possible choice for electric vehicles, yet it lacks the excellent power and energy density of $\mathrm{LiCoO}_{2}[12,13]$. In 1996, conception of $\mathrm{LiFePO}_{4}$ as a possible cathode for today's Li-ion batteries [14] came to life. This material, with olivine structure, has been a focal point for much experimentation and discussion as it boast several attractive qualities including a relatively high theoretical capacity of 170 $\mathrm{mAh} / \mathrm{g}$, great structure stability, long cycle life, environmentally benign qualities and most importantly, great thermal stability for safety [14]. Thermal stability testing by use of differential scanning calorimetry testing can determine a material's ability to absorb or emit heat during an electrochemical reaction. This test is usually performed to investigate exothermic and endothermic reactions for composite explosives but can also be used for lithium insertion and extraction reactions. Test data shows decomposition 
temperatures of $\mathrm{LiCoO}_{2}, \mathrm{LiMn}_{2} \mathrm{O}_{4}$ and $\mathrm{LiNiO}_{2}$ at $340^{\circ} \mathrm{C}, 275^{\circ} \mathrm{C}$ and $250^{\circ} \mathrm{C}$, respectively. $\mathrm{LiNiO}_{2}$ and $\mathrm{LiCoO}_{2}$ also show significant exothermic reactions, unfavorable for vehicle application as overheating could very easily occur [15]. $\mathrm{LiFePO}_{4}$, on the other hand, is endothermic, not releasing heat during the electrochemical reaction and decomposition doesn't take place until temperatures rise above $900^{\circ} \mathrm{C}$ [16]. Therefore, it is the safest material for vehicle and human sensitive applications.

However, there are drawbacks to $\mathrm{LiFePO}_{4}$. It yields a very low electronic conductivity, a property essential for battery design. But this property has been greatly improved through the successful application of conductive coatings or cation doping making it comparable with other cathode materials [8, 17, 18]. In addition to these attributes, the constituent materials are abundant and widely available at a relatively inexpensive price making $\mathrm{LiFePO}_{4}$ extremely attractive for high-power vehicle, military and space flight operations $[4,20]$ along with everyday consumer electronics.

\section{FACTORS FOR ELECTRODE FAILURE}

$\mathrm{LiFePO}_{4}$ is an anisotropic material with three different elastic moduli for each orthorhombic direction: $\mathrm{E}_{11}, \mathrm{E}_{22}$, and $\mathrm{E}_{33}$ apply to $\mathrm{a}=[100], \mathrm{b}=[010]$, and $\mathrm{c}=[001]$ principal directions [19] (Table 1). Because the material is anisotropic, phase transformation from $\mathrm{FePO}_{4}$ to $\mathrm{LiFePO}_{4}$ during intercalation will induce different strains in each direction (Table 2). Structural failure due to fracturing of active material is a main factor in battery degradation and overall capacitance loss after many cycles of use [19, 21-24].

TABLE 1: Orthorhombic material properties.

\begin{tabular}{|l|l|l|}
\hline Material Phase & LiFePO $_{\mathbf{4}}$ & FePO $_{\mathbf{4}}$ \\
\hline Orthotropic & $\mathrm{E}_{11}=133$ & $\mathrm{E}_{11}=167$ \\
Elastic Modulus & $\mathrm{E}_{22}=203$ & $\mathrm{E}_{22}=128$ \\
$(\mathrm{GPa})$ & $\mathrm{E}_{33}=172$ & $\mathrm{E}_{33}=121$ \\
\hline Poisson Ratio v & 0.30 & 0.23 \\
\hline Shear Modulus $(\mathrm{GPa})$ & 44 & 45 \\
\hline Bulk Modulus $(\mathrm{GPa})$ & 66 & 96 \\
\hline
\end{tabular}

Each time lithium ions are inserted into the cathode during the discharging process, a volumetric change of about $7 \%$ occurs which induces misfit strains as the phase transformation from $\mathrm{FePO}_{4}$ to $\mathrm{LiFePO}_{4}$ occurs (Table 2 and Figure 3). Stresses induced by the phase transformation strains may create flaws, or cracks that will be stress concentration areas when further cycling occurs. A combination of tensile and compressive stresses will induce microscopic crack propagation if critical values are reached. Over time and repeated cycling, fatigue crack propagation will continue for a finite number of cycles until the crack reaches a critical crack length where complete fracture initiates. When this active electrode material is fractured away, the battery will effectively loose capacitance and maximum power output diminishes. Thus, understanding the relationship between stresses and imperfections during lithium ion intercalation will be instrumental.
TABLE 2: Lattice parameters and misfit strain during lithium insertion from $\mathrm{FePO}_{4}$ to $\mathrm{LiFePO}_{4}$. Directions a, b and c refer to the axes in Figure 3. Values show tension in a and $b$, compression in c.

\begin{tabular}{|l|l|l|l|}
\hline & $\mathrm{FePO}_{4}$ & $\mathrm{LiFePO}_{4}$ & Misfit Strain \\
\hline $\mathrm{V}\left[\AA^{3}\right]$ & 288 & 297 & \\
\hline $\mathrm{a}[\AA]$ & 9.94 & 10.39 & $\varepsilon_{\mathrm{a}}=5.03 \%$ \\
\hline $\mathrm{b}[\AA]$ & 5.93 & 6.04 & $\varepsilon_{\mathrm{b}}=3.7 \%$ \\
\hline $\mathrm{c}[\AA]$ & 4.88 & 4.73 & $\varepsilon_{\mathrm{c}}=-1.9 \%$ \\
\hline
\end{tabular}

\section{FATIGUE ANALYSIS BASED ON MIXED MODE FRACTURE}

During a battery discharging operation, a transformation from $\mathrm{FePO}_{4}$ to $\mathrm{LiFePO}_{4}$ phase occurs as lithium diffuses from anode to cathode, inducing volumetric expansion and misfit stresses within the particle [19] (Table 2). The most prominent stresses arise at the phase boundary interface where tension is applied in the ' $a$ ' and ' $b$ ' directions and compression is observed in the 'c' direction of $\mathrm{LiFePO}_{4}[19,21,25,26]$ (Figure 3).

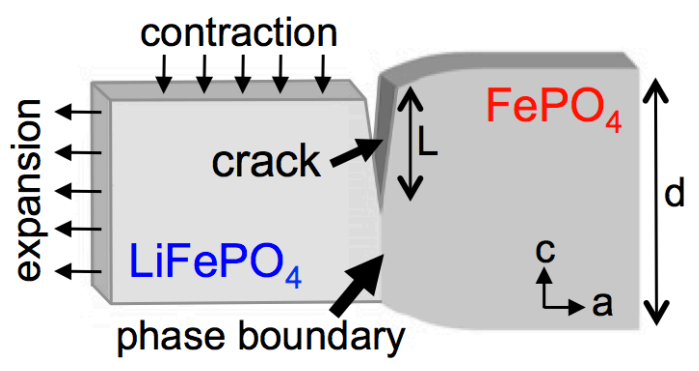

Figure 3: Particles undergo phase changes, in which $L$ represents the crack length and $d$ represents the particle size. Expansion occurs along the a-direction $\left(\varepsilon_{\mathrm{a}}=\mathbf{5 . 0 3 \%}\right)$, and extraction occurs along the c-direction $\left(\varepsilon_{\mathrm{c}}=-1.9 \%\right)$ (Table 2). The image was obtained courtesy of [23].

Pre-existing cracks in the electrode material are sites for stress concentrations and it is the focus of the current study. ANSYS finite element software (ANSYS, Inc. Canonsburg, Pennsylvania) is utilized to model the phase transformation process at the crack. A scaled up model of a $\mathrm{LiFePO}_{4}$ unit cell measures 200-nm x 120-nm x 90-nm and a crack is considered to run parallel to the bc-plane (along the c-axis) where phase boundaries are present (Figure 3). Figure 3 shows our finite element model, in which $\mathrm{L}$ represents the crack length and $\mathrm{d}$ represents the particle size. Nine finite element simulations are conducted for cracks of sizes $\mathrm{L} / \mathrm{d}=0.05-0.8$, where $\mathrm{L}$ is the crack length and $d$ is the length of the particle parallel to the cracking direction. Displacements were applied to the $\mathrm{LiFePO}_{4}$ phase according to the misfit strains previously measured and reported in literature (Figure 3). This initial flaw is applied from the top face with variable length from $0.05-0.8 \mathrm{~L} / \mathrm{d}$ and the crack opening is set as $0.5 \mathrm{~nm}$ to stay proportional to experimentally observed cracks [21]. Assuming displacements along the a- and c-axes are independent of b-axis and there are no normal tractions on the ac-plane, the plane stress assumption 
is applied. The model is reduced to a $200-\mathrm{nm} \times 90-\mathrm{nm} 2 \mathrm{D}$ plate, viewed on the ac-plane. Although crack propagation is possible in other planes, literature and experimentations report cracks observed in the bc-plane between phases while propagating in the c direction [27]. The olivine crystal structure of $\mathrm{LiFePO}_{4}$ and the Third Pauli's Rule supports this observation: (100) planes are linked through stable, shared corner bonds between $\mathrm{FeO}_{6}$ octahedra and $\mathrm{PO}_{4}$ tetrahedra while (010) planes are connected together by weaker, edge-sharing bonds between $\mathrm{FeO}_{6}$ octahedra [21]. 2D quadrilateral elements of type PLANE 183 are used in our finite element analysis, and the model is densely meshed around the crack tip to a size of $5 \mathrm{E}^{-10}$ $\mathrm{m}$ (Figure 4). PLANE 183 elements were chosen as the eight node structure allows for more flexibility and improved accuracy in contrast to four node, PLANE182 elements.

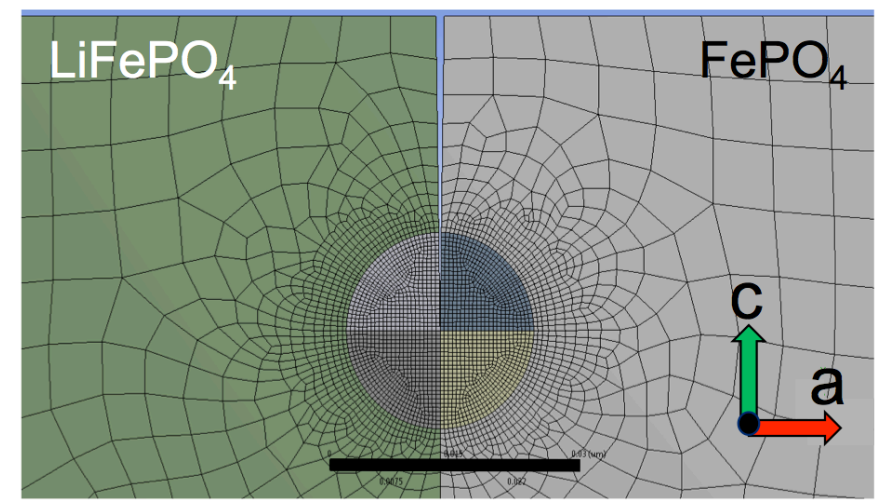

Figure 4: Finite element meshes at the crack tip. Scale bar $=$ $0.03 \mu \mathrm{m}$.

First introduced by Irwin, the basis for strain energy release rate (SERR) is to find the change in elastic energy per change in crack size [28]. Energy release rates, G, are one of the most important fracture mechanics parameters for isotropic or orthotropic materials [28] and it is part of the basis for linear elastic fracture mechanics. In this study, $G$ values will be utilized with the simple plane stress assumption to elucidate cracking tendency for a given sized crack in a particle under cycling stress. An advancing crack will increase the crack surface area, but at the same time decreases the elastic energy in the particle. A crack can no longer propagate if the SEER is less than approximately two times the surface energy of the particle $(\mathrm{G}<2 \gamma)[28]$.

The rate of discharge will determine resultant stresses within the material which will in turn control the SERR at a crack in the particle. Larger stress in a shorter period of time may induce cracking more readily than for slower discharging rates. This is due to the limited volumetric expansion rate unable to satisfying the rate of lithium diffusivity during fast discharging, similar to rush hour traffic in limited highway space. Therefore, one potential future consideration is to reduce the particle size of $\mathrm{LiFePO}_{4}$ electrode particles to effectively reduce the diffusion path and decrease stress inside the particle [29]. The strain energy release rate is calculated by ANSYS using fracture mechanics based on Irwin's virtual crack closure technique (VCCT) method. The theory behind VCCT is that the energy needed to separate a surface is the same as the energy needed to close the surface back on itself [25]. Using a proper mesh and several commands in ANSYS, the VCCT method calculates relative displacements $(\mathrm{u}, \mathrm{w}, \mathrm{a})$ and reaction forces $(\mathrm{X}, \mathrm{Z})$ which then are formulated to produce energy release rates as depicted in Figure 5 [30].

$$
\begin{aligned}
& G_{I}=\frac{-\left[X_{1}\left(\Delta u_{1}\right)+X_{2}\left(\Delta u_{2}\right)\right]}{2 \Delta a} \\
& G_{I I}=\frac{-\left[Z_{1}\left(\Delta w_{1}\right)+Z_{2}\left(\Delta w_{2}\right)\right]}{2 \Delta a}
\end{aligned}
$$

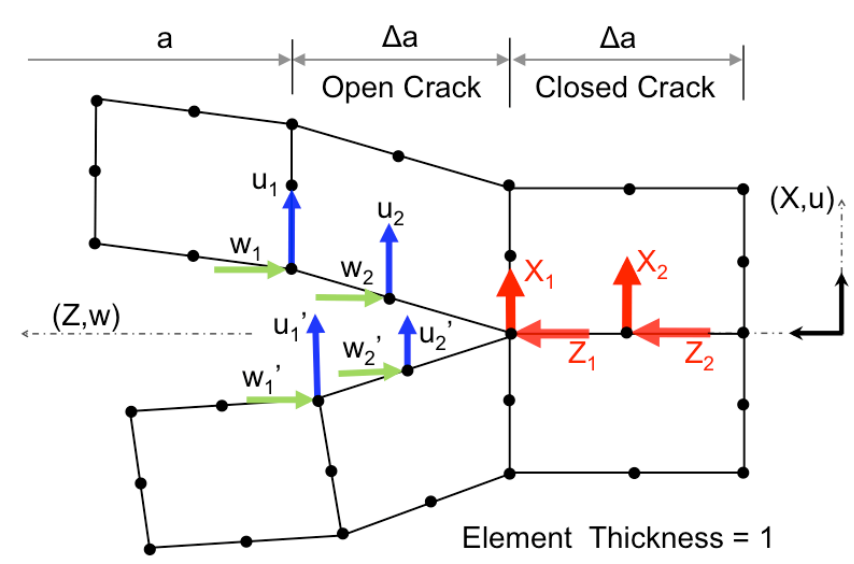

Figure 5: VCCT method for 2D quadrilateral elements. Energy release rates are calculated via the crack size $(\Delta a)$, reaction forces $(Z$ and $X)$, and relative displacements $(u, w$, and $a)$.

\section{RESULTS}

Figure 6 shows the stress fields for an entire particle between phases. Shades of purple and green represent areas of compression and tension, respectively. Shades of white express minimal or zero stress areas. Overall, normal stresses dominate as compared to shear stress throughout the particle.

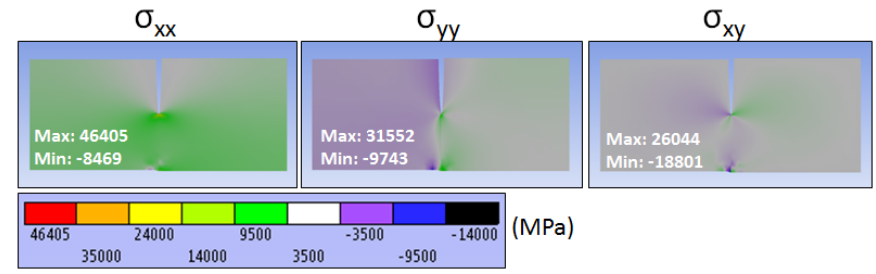

Figure 6: Stress fields for an entire particle between phases. $\mathrm{L} / \mathrm{d}=\mathbf{0 . 5}$ sized crack.

Table 3 tabulates the SERR G values and stress intensity factors (SIF) data. Mode 1 (opening) is dominant but Mode 2 (in plane shear) also contributes. Mode 3 (out of plane shear) is non-existent in the plane stress model. GT is the total strain energy release rate, and it is a combination of modes I and II. The cracking mode during the propagation is a resultant of applied stresses, elastic moduli values, and therefore resultant stress intensity factors $\left(\mathrm{K}_{\mathrm{I}}\right.$ and $\left.\mathrm{K}_{\mathrm{II}}\right)$ are calculated for each 
simulation to predict the state of stress around the crack tip. Specific reasoning behind the magnitude of Mode I and Mode II magnitudes directly relates to a combination of misfit strains and anisotropic elastic moduli values. The a-direction $\left(\mathrm{E}_{11}\right)$ value for $\mathrm{LiFePO}_{4}$ is much smaller than the other orthorhombic directions (Table 1). The material is weaker in this direction giving away to the splitting or opening, Mode I type of fracture.

TABLE 3: Strain energy release rates (G, units of $N / m)$ and stress intensity factors $\left(\mathrm{K}\right.$, units of $\left.\mathrm{MPa} \times \mathrm{m}^{1 / 2}\right)$ at the crack tip.

\begin{tabular}{|c|c|c|c|c|c|}
\hline $\mathrm{L} / \mathrm{d}$ & $\mathrm{G}_{\mathrm{I}}$ & $\mathrm{G}_{\mathrm{II}}$ & $\mathrm{G}_{\mathrm{T}}$ & $\mathrm{K}_{\mathrm{I}}$ & $\mathrm{K}_{\mathrm{II}}$ \\
\hline 0.05 & -0.081 & 0.009 & 0.090 & 0.414 & -0.277 \\
\hline 0.1 & -0.110 & 0.015 & 0.125 & 0.616 & -0.344 \\
\hline 0.2 & 4.248 & 0.506 & 4.755 & 0.787 & -0.212 \\
\hline 0.3 & 5.717 & 0.358 & 6.075 & 0.910 & -0.162 \\
\hline 0.4 & 6.610 & 0.250 & 6.860 & 0.977 & -0.123 \\
\hline 0.5 & 7.052 & 0.158 & 7.210 & 1.007 & -0.085 \\
\hline 0.6 & 7.206 & 0.079 & 7.285 & 1.043 & -0.080 \\
\hline 0.7 & 7.252 & 0.026 & 7.278 & 1.069 & -0.027 \\
\hline 0.8 & 7.402 & 0.017 & 7.403 & 1.074 & 0.048 \\
\hline
\end{tabular}

Figure 7 revealed that SEER is highly dependent on the crack size. One critical point starts at around $\mathrm{L} / \mathrm{d}=0.5$, where release rates are very high and then begin to level off. If an applied stress is large enough to propagate a crack at $\mathrm{L} / \mathrm{d}=0.5$, the same applied stress will also be large enough to continue propagation for future cycling at larger $\mathrm{L} / \mathrm{d}$ values (longer cracks than $\mathrm{L} / \mathrm{d}=0.5$ ). Therefore, this is the maximum $\mathrm{L} / \mathrm{d}$ point that needs to be considered to determine if a crack will extend during lithiation.

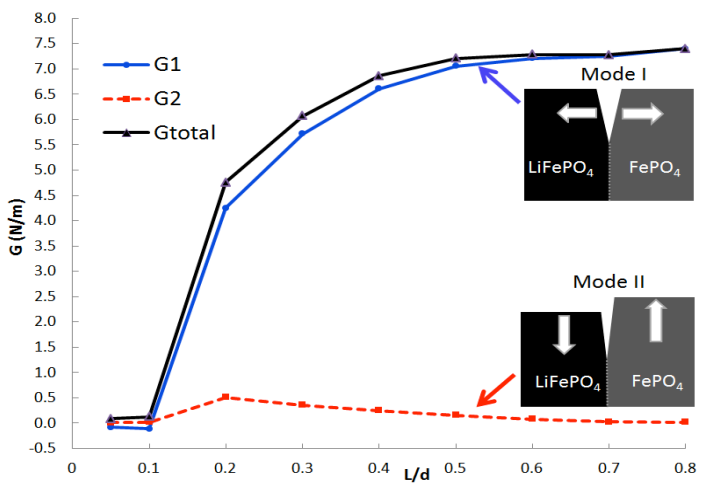

Figure 7: Energy release rates at crack tip for models with nine different $L / d$ ratios. It is observed that Mode $I$ cracks are likely to occur and propagate, especially when $L / d=0.5$.

Stress intensity factors are also calculated in the study to further delineate differences between Mode 1 and Mode II cracks near the crack tips (Figure 8). It is observed that Mode I SIF reaches a relative maximum value of 1.0 when $\mathrm{L} / \mathrm{d} \geq 0.5$. In contrast, Mode II SIF continues to decrease towards zero (under compression) while cracks become larger. Corresponding stress fields at crack tips for $\mathrm{L} / \mathrm{d}=0.1,0.4$ and 0.7 are shown in Figure 11. In very short cracks, $\sigma_{y y}$ contributes the most stress as the particle begins to experience a large magnitude of Mode II (in plane shear) from compression the in the c-direction. But as the cracks grow deeper, $\sigma_{\mathrm{xx}}$ increases showing a transition to Mode I (opening) dominance near the crack tip. $\tau_{\mathrm{xy}}$ remains small for short cracks but larger compressive stresses develop with crack growth.

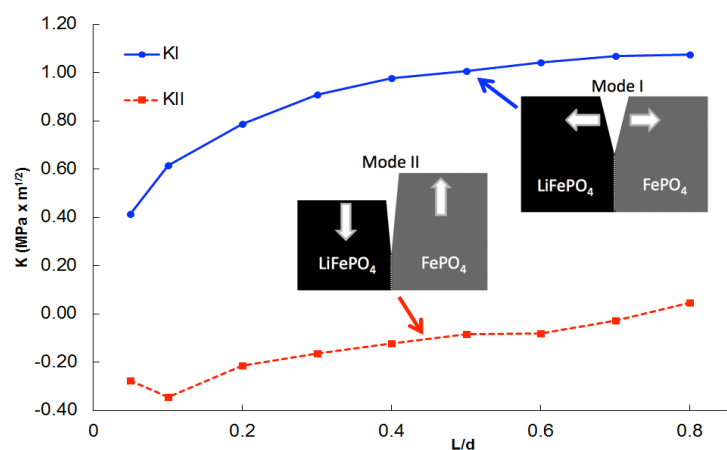

Figure 8: Mode I and Mode II stress intensity factors at crack tips with nine different $L / d$ ratios.

It is concluded that cracks propagate to relieve internal stresses. To predict fatigue crack growth, total strain energy release rates $\left(\mathrm{G}_{\mathrm{T}}\right)$ and surfaces energies $(\boldsymbol{Y})$ are compared and allow for propagation when $\mathrm{G}>2 \boldsymbol{\Gamma}$. A first-principles analysis by Wang et al reports a $\boldsymbol{Y}$ value of $0.66 \mathrm{~N} / \mathrm{m}$ for $\mathrm{LiFePO}_{4}$ in the (100) crack face orientation [31]. Therefore, once $\mathrm{G}_{\mathrm{T}}$ increases above $1.32 \mathrm{~N} / \mathrm{m}$, crack propagation is eminent and a crack will grow until the surface energy from the newly formed crack faces brings the particle back to equilibrium with the strain energy release rate. Depending on the crack face surface area and $G_{T}$ value for an initial flaw under stress, the difference in energies and required surface area for equilibrium can be calculated and related to a finite crack length for a single Liinsertion cycle. An iterative MATLAB program is utilized to recalculate required energy and crack length advancement until complete fracture in the particle. The number of cumulative cycles is recorded and shown in Figure 10. A fatigue life estimate is created by plotting the crack advancement per cycle versus the change in stress intensity factor. This relationship is described by the Paris Law (Figure 9).

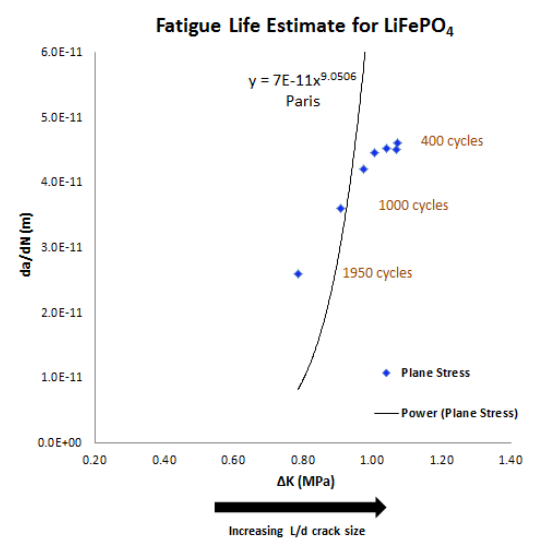

Figure 9: The fatigue life plot shows Paris Law constants of $C=7 \times 10^{-11}$ and $m=9.05$. 


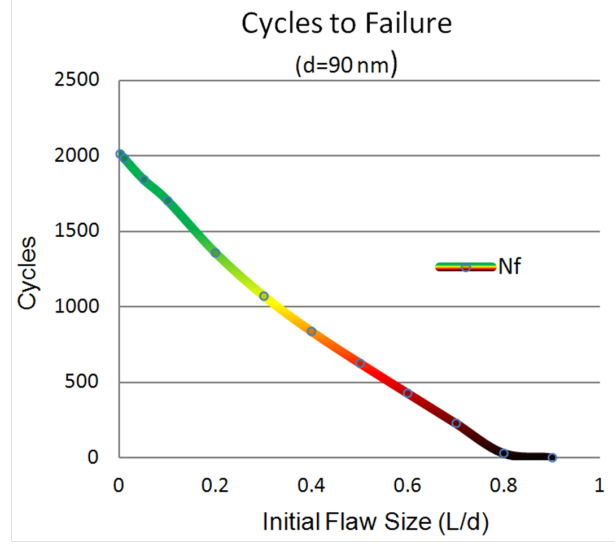

Figure 10: Maximum value of 2012 cycles attained with $0.1 \mathrm{~nm}$ size initial flaw for $\mathrm{LiFePO}_{4}$. Cycles decrease steadily as initial flaw size increases. Colors from green to yellow to red represent good, marginal, and poor cycle life as pertaining to EV and PHEV.

The USCAR (United States Council for Automotive Research LLC) reports benchmark objectives of 10 years (EV) and 15 years (PHEV) for all future batteries [32]. U.S. Department of Energy research shows that a Chevy Volt PHEV undergoes 17 partial charging events per month and a Nissan Leaf EV can travel about 70 miles per full charge [33]. Assumptions equate this data to 2 full charges per week per vehicle. The feasibility of using $\mathrm{LiFePO}_{4}$ cathode batteries can be assessed using Figure 10 after calculations indicate the need for 1050 (EV) and 1550 (PHEV) cycles till dead on discharge. Battery electrodes with a Weibull distribution of initial flaws less than or equal to about $0.3 \mathrm{~L} / \mathrm{d}$ and $0.15 \mathrm{~L} / \mathrm{d}$ will be able to achieve the 10 year and 15 year cycle life's needed for EV and PHEV use, respectively.

\section{CONCLUSION}

In summary, the foundation for a fatigue analysis of lithium-ion cathode materials is provided. Material properties are obtained from literature and ANSYS FEA software is utilized to model flawed particles and generate strain energy release rates and stress intensity factor data. Results show that if crack propagation occurs after reaching $\mathrm{L} / \mathrm{d}=0.5$, continued cycling at the same rate and stress values will assure continued propagation as the crack grows. Between $\mathrm{L} / \mathrm{d}=0.05$ and 0.5 , the maximum $G$ value shown in Figure 7 can be compared to surface energy values of the fracture to determine if a crack will propagate. Cracking modes were also taken into consideration showing a Mode II fracture type for very short cracks, which gives way to Mode I dominance in intermediate and very long cracks (Figure 11). A fatigue life plot is presented after comparing strain energy release rates and surface energy of the initially fractured surface. Cycle life results show a theoretical life limit of 2012 cycles which is near reported values in literature and manufacturer websites [34,35].

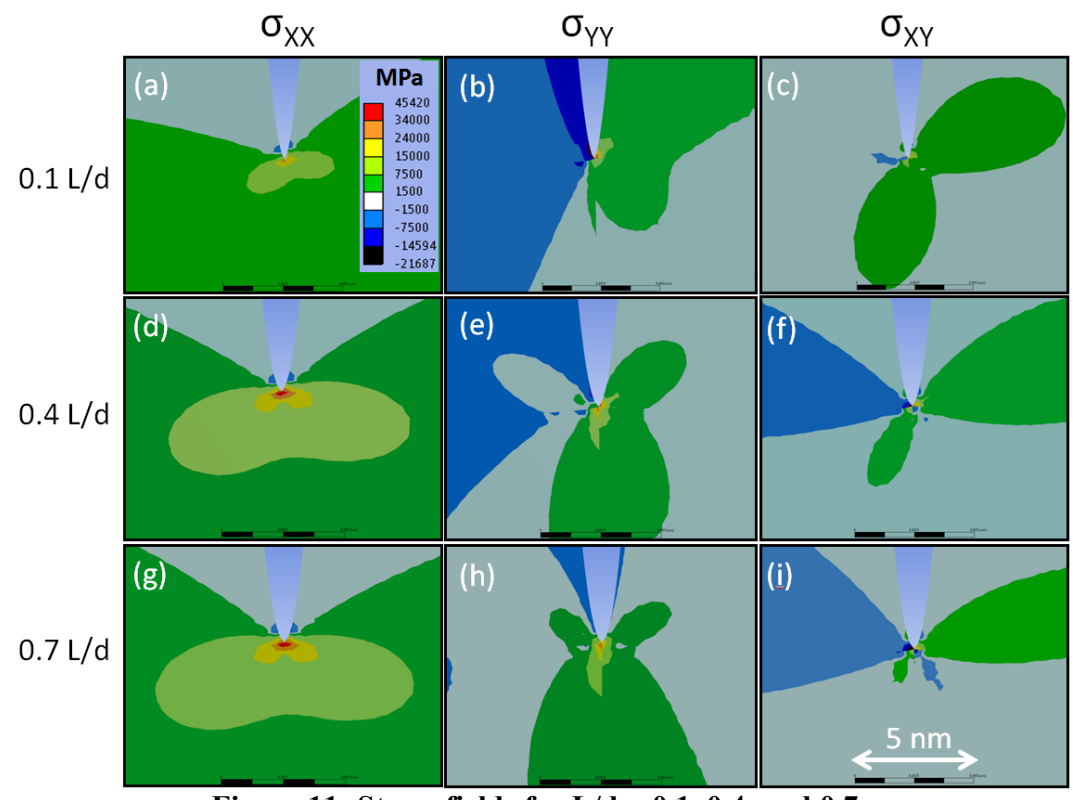

Figure 11: Stress fields for $L / d=0.1,0.4$, and 0.7 .

This is a first approach towards improving battery structural design by providing a better understanding of micromechanics and a base for future fatigue analyses which may incorporate a variety of electrode materials and additional fatigue life parameters. Two such parameters include the application of nano-layer coatings to increase electronic conductivity and fracture toughness along with reducing particle size to effectively reduce the diffusion path and decrease internal stress within the particle [29]. This research will hopefully elucidate a relationship between micromechanics and battery usage to help in the design of a higher performance, longer lasting battery for the future. 


\section{REFERENCES}

[1] Anonymous 2011, "Comprehensive Energy Policy, Land Institute 501 c(3) Organization."

[2] Energy Information Administration, U. S., 2009, "Emissions of Greenhouse Gases in the United States", 2008. U.S. Department of Energy, DOE/EIA 0573(2008), Office of Energy.

[3] (National Highway Traffic Safety Administration), NHTSA, 2011, "2016 Policy Minimum Requirements."

[4] Howell, D., Duong, T., Deppe, J., 2008, "U.S. Department of Energy's Material Research for Advanced Lithium Ion Batteries: DOE Vehicle Tech Program," Material Matters, 3(4) pp. 100.

[5] Awarke, A., Lauer, S., and Pischinger, S., 2011, "PercolationTunneling Modeling for the Study of the Electric Conductivity in LiFePO4 Based Li Ion Battery Cathodes," Journal of Power.

[6] U.S. Energy Information Administration, EIA, 2010, "Annual Energy Review."

[7] U.S. Energy Information Administration, EIA, 2011, "Annual Energy Review."

[8] Chung, S. Y., Bloking, J. T., and Chiang, Y. M., 2002, "Electronically Conductive Phospho-Olivines as Lithium Storage Electrodes," Nature Materials, 1(2) pp. 123-128.

[9] American Physical Society, 2012, "Lithium Ion Batteries."

[10] Cheon, S. E., Kwon, C. W., and Kim, D. B., 2000, "Effect of Binary Conductive Agents in $\mathrm{LiCoO}_{2}$ Cathode on Performances of Lithium Ion Polymer Battery," Nature Materials, 1(2) pp. 123-128.

[11] Shaju, K. M., and Bruce, P. G., 2008, "Stoichiometric Nano$\mathrm{LiMn}_{2} \mathrm{O}_{4}$ Spinel Electrode Exhibiting High Power and Stable Cycling." Chem. Material, 20(17) pp. 55-62.

[12] Liu, P., Sherman, E., and Verbrugge, M., 2010, "Electrochemical and Structural Characterization of Lithium Titanate Electrodes," Journal of Solid State Electrochemistry, 14(4) pp. 585-591.

[13] Chan, C. K., Peng, H., and Liu, G., 2008, "Performance Lithium Battery Anodes using Silicon Nanowires," Nature Nanotechnology, 3(1) pp. 31-35.

[14] Padhi, A. K., Nanjundaswamy, K. S., and Goodenough, J. B., 1997, "Phospho-Olivines as Positive-Electrode Materials for Rechargeable Lithium Batteries," Journal of the Electrochemical Society, 144(4) pp. 1188-1194.

[15] Xia, Y., Fujieda, T., and Tatsumi, K., 2001, "Thermal and Electrochemical Stability of Cathode Materials in Solid Polymer Electrolyte," Journal of Power Sources, 92(1-2) pp. 234-243.

[16] Gao, J., Jianjun, L., Xiangming, H., 2001, "Synthesis and Electrochemical Characteristics of $\mathrm{LiFePO}_{4} / \mathrm{C}$ Cathode Materials from Different Precursors," Int. J. Electrochem Sci., 6pp. 2818-2825.

[17] Delacourt, C., Poizot, P., Tarascon, J. M., 2005, "The Existence of a Temperature-Driven Solid Solution in $\mathrm{Li}_{\mathrm{x}} \mathrm{FePO}_{4}$ for $\mathrm{c}<\mathrm{x}<1$," Nature Materials 4, pp. 254-260.

[18] Bai, Y., Qiu, P., Wen, Z., 2010, "Improvement of Electrochemical Performances of $\mathrm{LiFePO}_{4}$ Cathode Materials by Coating of Polythiophene," Journal of Alloys and Compounds, 508(1) pp. 1-4.

[19] Maxisch and Ceder, 2006, "Elastic Properties of Olivine $\mathrm{Li}_{\mathrm{x}} \mathrm{FePO} 4$ from First Principles," Physical Review B 73, 174112.

[20] Reid, M., Concha, 2007, "Lithium Iron Phosphate Cell Performance Evaluations for Lunar Extravehicular Activities," NASA Glenn Research Center.

[21] Gabrisch et al, 2008, "TEM Study of Fracturing in Spherical and Plate-Like LiFePO4 Particles," Electrochemical and Solid-State Letters, 1193 pp. A25-A29.

[22] Zhao, K., Pharr, M., Vlassak, J. J., 2010, "Fracture of Electrodes in Lithium-Ion Batteries Caused by Fast Charging," Journal of Applied Physics, 108(7) (073517).
[23] Hu, Y., Zhao, X., and Suo, Z., 2010, "Averting Cracks Caused by Insertion Reaction in Lithium-Ion Batteries," Journal of Materials Research, 25(6) pp. 1007-1010.

[24] Renganathan, S., Sikha, G., Santhanagopalan, S., 2010, "Theoretical Analysis of Stresses in a Lithium Ion Cell," Journal of the Electrochemical Society, 157(2) pp. A155-A163.

[25] Agrawal, A., and Karlsson, A. M., 2006, "Obtaining Mode Mixity for a Biomaterial Interface Crack using the Virtual Crack Closure Method," Int J Fract, (141) pp. 75-98.

[26] Meethong, N., Huang, H. S., Speakman, S. A., 2007, "Strain Accommodation during Phase Transformations in Olivine-Based Cathodes as a Materials Selection Criterion for High-Power Rechargeable Batteries," Advanced Functional Materials, 17(7) pp. 1115-1123.

[27] Chen, G. Y., Song, X. Y., and Richardson, T. J., 2006, "Electron Microscopy Study of the LiFePO4 to FePO4 Phase Transition," Electrochemical and Solid State Letters, 9(6) pp. A295-A298.

[28] Sanford, R.J., 2003, "Principles of Fracture Mechanics," Prentice Hall, Upper Saddle River, NJ.

[29] Woodford, W. H., Chiang, Y., and Carter, W. C., 2010, "Electrochemical Shock" of Intercalation Electrodes: A Fracture Mechanics Analysis," Journal of the Electrochemical Society, 157(10) pp. A1052-A1059.

[30] Krueger, R., 2004, "Virtual Crack Closure Technique: History, Approach, and Applications," Applied Mechanics Reviews, 57, 2.

[31] Wang, L.,Zhou, F.,Meng,Y.S.,Ceder, G., 2007, "First-Principles Study of Surface Properties of LiFePO4: Surface Energy, Structure, Wulff Shape, and Surface Redox Potential," Physical Review B, 76(165435) pp. 1-11

[32] USCAR, United States Council for Automative Research LLC, 2012, "U.S. Advanced Battery Consortium: Energy Storage System Goals."

[33] Francfort, J., 2012, "U.S. Department of Energy's Vehicles Technology Program," Idaho National Lab, SAE Government/Industry Meeting Washington D.C., Jan 2012.

[34] Borgasano, D., and A123 Systems PR Contact, 2012, " A123 Systems Introduces Breakthrough Lithium Ion Battery Technology that Optimizes Performance in Extreme Temperatures," 2012 (July/10).

[35] EEMB Battery, 2011, "EEMB Designed LiFePO4 Battery with Long Cycle Life," 2012 (July/10). 